\title{
Blended learning in Saudi universities: challenges and perspectives
}

\author{
Reem Alebaikan* and Salah Troudi \\ University of Exeter, UK \\ (Received 29 November 2008; final version received 5 July 2009)
}

\begin{abstract}
This study is an attempt to investigate the nature of obstacles and challenges encountered at Saudi universities while implementing a blended learning approach. A literature review of blended learning rationale and designs, and the status of web-based education in Saudi higher education are demonstrated. Three main challenges of applying blended learning in Saudi higher education are addressed. One major challenge to be considered in the implementation of blended learning in Saudi universities is the adaptation of this element in the traditional university culture. Finding the right design of blended learning is another challenge that is discussed in detail. Furthermore, the time issue is considered a crucial challenge facing blended learning faculty. Practical recommendations that would facilitate transition to a blended learning university environment are presented. It is hoped that this study will help to provide insight for the faculties and the decision-makers throughout higher education in Saudi Arabia. Although this investigation is specifically related to the implementation of blended learning in the universities of Saudi Arabia, we are confident that the assumptions and recommendations contained herein will be of great value to other populations facing similar challenges.
\end{abstract}

Keywords: blended learning; challenges of blended learning; higher education; Saudi Arabia

\section{Introduction}

The Saudi Ministry of Higher Education has encouraged the use of information technology (IT) for teaching and learning among its faculties and students. Projects are continuously developed to provide adequate IT infrastructure as well as content development for higher education students. One of the major challenges encountered in Saudi higher education is to provide college education to the rapidly growing student population in the country. The capacity of universities and colleges in Saudi Arabia is limited compared with the rapid growth of students applying for college education. To tackle this problem, the Ministry of Higher Education endeavours to integrate webbased instruction with traditional instruction in universities.

Around the world, various academic practices have been used to explore blended learning, its effectiveness and challenges. Rooney (2003) declared that blended learning has been identified by the American Society for Training and Development as one of the top 10 trends to emerge in the knowledge delivery industry. Although there are a wide variety of designations for blended learning, the most common

*Corresponding author. Email: alebaikan@gmail.com 
blended learning definition refers to an integration of online activities and traditional face-to-face class activities. Graham, Allen, and Ure (2003) documented three definitions: combining instructional modalities or delivery media, combining instructional methods, and combining online and face-to-face instruction. The first two definitions are too broad because they include most courses, which use at least two instruction methods or modalities (i.e. face-to-face lecture and textbook readings). The last definition, which combines online and face-to-face instruction, can be implemented in three ways: providing online materials similar to the course contents, providing online materials as supplementary resources, and replacing portions of the face-to-face contents with online materials. Sharpe et al. (2006) observed that the most common type of blended learning is the provision of supplementary resources for courses that are conducted along mainly traditional lines through an institution-supported virtual learning environment. Moreover, at the 2005 Sloan-C Workshop on Blended Learning, the participants adopted the definition of blended learning where a portion of face-to-face time is replaced by online activity in a planned, pedagogically valuable manner (Laster et al. 2005; Picciano 2006). In this study, the Sloan-C workshop blended learning definition is used because it matches the goal of the e-learning project in the Saudi Ministry of Higher Education. This goal is to adopt blended learning that combines e-learning and traditional learning, in which students do not need $100 \%$ class attendance whilst keeping in touch with faculty members through online learning (Al-Ahmari 2009; Abdul Ghafour 2008).

In the next sections, the rationale for blended learning and various blended learning designs are presented. This study demonstrates the status of web-based education in higher education in Saudi Arabia. The challenges of applying blended learning in Saudi higher education are discussed. It is hoped that this study will help to provide insight for the faculties and the decision-makers throughout higher education in Saudi Arabia.

\section{Rationale for blended learning}

Innovations in technology have influenced teaching and learning, as shown in studies that have demonstrated the effectiveness of blended learning. This effectiveness is primarily related to the quality of the learning experience, which is defined by Wend (2006) as the variety of experiences within the university's concerns wherein students perceive and interact; thereby in turn affecting their learning opportunities. In order to provide quality experiences for learners, some important elements have to be managed, such as technology, the structure of the course, the instructor, technical support, assignments (Lionarakis and Parademetriou 2003), student engagement (Oliver and Herrington 2003) and learning flexibility.

Blended learning has been implemented with various designs and has shown a considerable positive effect on the learning process. Harvard Business School faculty DeLacey and Leonard (2002) reported that students not only learned more when online sessions were added to traditional courses, but student interaction and satisfaction improved as well. Obviously, the most common purpose of blended learning is the ability of combining the best of both worlds; traditional and online learning (Young 2002; Graham, Allen, and Ure 2003). Young (2002) points out that not all students learn the same way, therefore the traditional approach is not ideal for all students. Blended learning provides more guidance to online learning by integrating 
face-to-face learning with distance learning, while it provides flexibility and accessibility to traditional learning by incorporating online learning.

Moreover, blended learning is appropriate for students who live far away from the university or have other commitments that conflict with the on-campus class time. Distance learning programmes may not provide the learning environment students require or may not provide specific degrees such as studies that require experimental work. Moreover, Sharpe et al. (2006) point out that blended learning designs have been implemented in higher education courses to tackle problems created by large group sizes. Studies have overwhelmingly shown that blended learning is used to improve pedagogy, increase cost-effectiveness, access and flexibility, and simplify revision (Graham, Allen, and Ure 2005; Osguthorpe and Graham 2003).

A study by Owston, Garrison, and Cook (2006) about blended learning in Canadian universities observed that instructors of a Canadian university assured that face-to-face contact was necessary for some first-year university students who need more guidance, which was the purpose for transforming fully online course to a blended format. Also, studies from institutions such as Stanford University and the University of Tennessee have proven that blended learning is better than both traditional methods and individual forms of e-learning technology alone; Singh and Reed state that "these researches give us confidence that blending not only offers us the ability to be more efficient in delivering learning, but more effective" $(2001,6)$.

A review of UK undergraduate experience of blended learning by Sharpe et al. (2006) concluded that a number of UK universities utilised blended learning to provide flexibility of provisions, and enhance campus experiences. Some universities promote blended learning as a strategy, particularly offering flexibility in the time and place of learning. In addition, implementing blended learning in some universities was in response to the practical challenges being encountered by faculties and/or in response to student feedback such as poor staff-student contact, large classes and inconsistency in quality and quantity of feedback between markers. Finally, institutions that had been identified by Sharpe et al. (2006) as successful implementers of blended learning had highly contextualised and specific rationales for their adoption of technology.

\section{Blended learning in Saudi universities}

\section{Web-based education}

Internet access has been available to the public in Saudi Arabia since 1999. In December 2000 there were approximately 200,000 Internet users in Saudi Arabia, and by 2005 this number had grown to 2.54 million, making the growth $1170 \%$ (Communications and Information Technology Commission 2007). Importantly, the number of the Internet users has jumped to 6.4 million in 2007, which is nearly one-third of the Saudi population that is about 24 million (see Figure 1). One reason for the growth is that about $60 \%$ of the Saudi population is comprised of young people who are 20 years old or younger (ArRiyadh Development Authority n.d.), and they are adapting to new technologies faster than expected. It is estimated that Internet use will continue growing rapidly in Saudi Arabia, which raises an issue of providing new learning strategies that include use of technology.

To meet the growing demand for higher education in the country, 19 public universities have been established and distributed around the country, four of which opened in 2005 (Ministry of Higher Education n.d.). A few private universities and colleges 


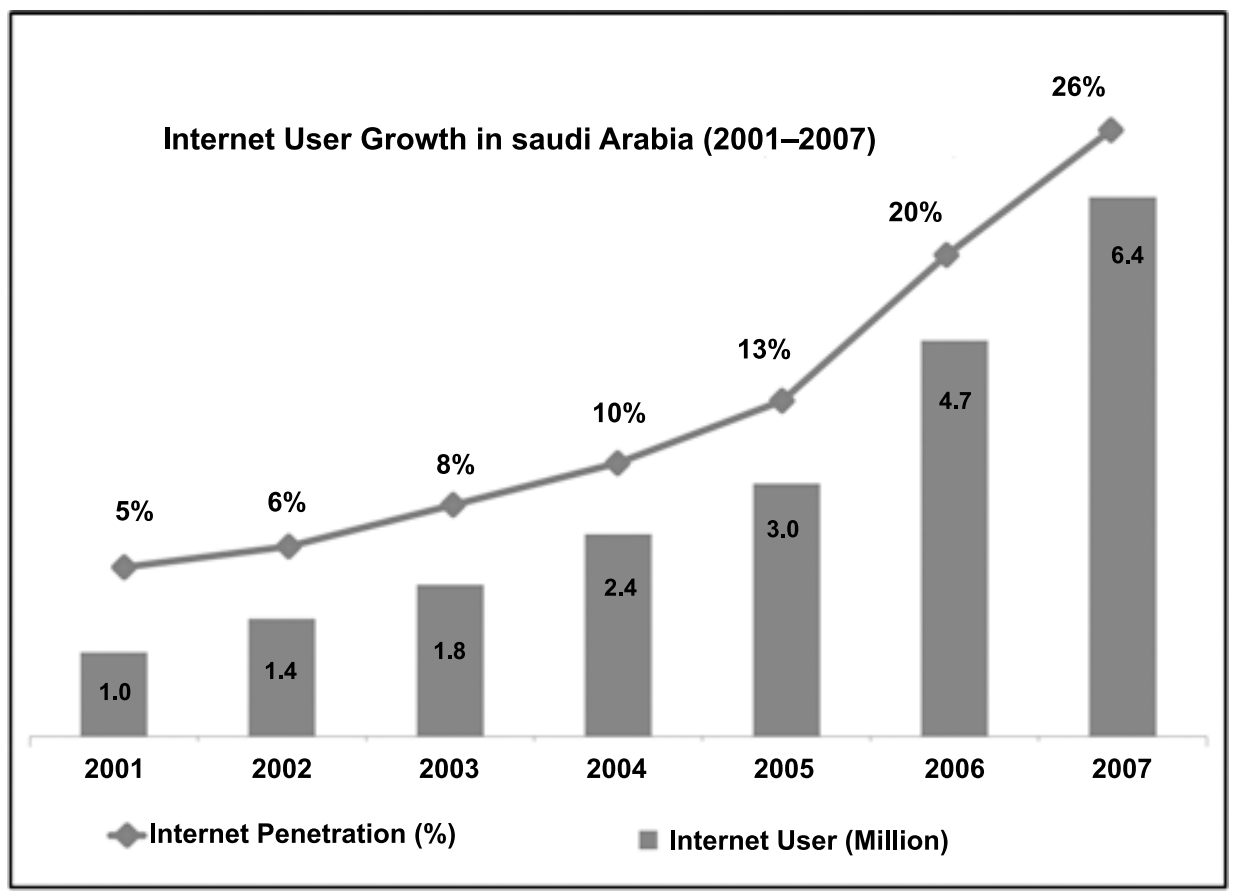

Figure 1. Internet users in Saudi Arabia.

Source: http://www.citc.gov.sa.

have been established recently such as the Arabic Open University and King Sultan University. There were only two public universities located in Riyadh, the capital of Saudi Arabia - namely, King Saud University and Imam Muhamed Bin Saud University - which are considered to be the two largest universities in Saudi Arabia. In early 2007, the public Girls Colleges located in Riyadh have been converted to a new public university known as Prince Nora bint Abdulrahman University. The traditional didactic, lecture-based classroom is the standard in Saudi public universities, with a few programmes implementing distance learning. Recently, some universities have started to undertake web-based instruction in their distance learning programmes.

In recent years, some universities and institutions have provided different commercial learning management systems, such as Blackboard, WebCT, and Tadarus (an Arabic-based learning management system) to facilitate learning and teaching online. However, the number of faculty members utilising these systems is very limited. One reason could be that the universities and institutions do not provide enough training workshops for online learning systems. A few faculty members, who are interested in e-learning and have adequate skills, provide online materials as supplementary resources for their courses. A few years ago, two universities namely, King Fahd University of Petroleum \& Minerals and King Abdulaziz University - established e-learning centres that provide assistance to their faculties to develop interactive web-based supplementary material for traditional courses. King Abdulaziz University, located in Jeddah, was the first Saudi university that employed a virtual learning environment by offering bachelor degrees through online learning. Imam Muhamed Bin Saud University began offering a distance learning programme that delivers instruction entirely through the Internet in August 2007. 


\section{New trend in higher education}

For the sake of developing education systems in Saudi Arabia, the Ministry of Higher Education has established the National Plan for Information Technology that encourages e-learning and distance education in higher education. In 2006, the National Plan for Information Technology established a national centre called the National E-learning and Distance Learning Centre (NELC). The NELC provides technical support, tools, and the means necessary for development of digital educational content in higher education throughout the country, and is a vehicle by which all university sectors can become standardised. Due to the huge population explosion and few qualified faculty members, the National Centre for E-Learning has started several projects that aim to enhance e-learning in Saudi universities (NELC n.d.). The NELC strives to provide rich multimedia resources to enable faculty members to integrate blended learning that fits their course and university needs.

The NELC has established a learning management system called 'Jusur' promoting materials for introductory undergraduate courses. The College of Application Studies at King Saud University started employing 'Jusur' in fall 2007 in a blended learning application. The students have been required to use the system to download and submit homework, and to participate via the discussion board of each course. There have been not any pilot studies prior to this first application of blended learning in Saudi public universities. It is expected that the use of blended learning for teaching and training will continue to grow in the coming years. In addition, it is notable that asynchronous online elements will be utilised due to Internet bandwidth limitation.

\section{Previous research in Saudi Arabia}

With the rapid evolution of IT in education in Saudi Arabia, many studies have been conducted to investigate the effect of online learning and the Internet on education, and more specifically on students. However, studies on blended learning in Saudi Arabia are still very scarce and all except one study investigated integrating face-toface learning with online learning as a supplementary resource.

Sait et al. (2003) conducted a study about the use and effect of Internet on instructors and students in Saudi Arabia and found that most instructors realise the potential of the Internet for education and understand the effort involved in effectively utilising this valuable resource. The results of the study asserted that training programmes would be essential. The majority of instructors believed that the Internet resources had helped improve curricula and teaching methods. In addition, they urged for new technological methods to be supplemental to traditional classroom teaching and not as a replacement.

The effect of blended learning on students' computer and mathematics attitudes in a Saudi Arabian university was investigated by Yushau (2006). Two modes of learning implemented during the experiment were face-to-face learning, three times a week, and online learning consisting of a weekly computer laboratory session with availability of online learning resources in the intranet and Internet to the students. The results indicated that the students have positive attitudes towards mathematics and computer.

Moreover, Al-Jarf (2005) conducted a study in a Saudi Arabian university to find out whether or not integration of online learning with face-to-face grammar instruction significantly improves English-as-a-foreign-language freshman college students' achievements and attitudes. The study concluded that in learning environments where 
technology is unavailable to English-as-a-foreign-language students and instructors, use of an online course from home as a supplement to in-class techniques helps motivate and enhance English-as-a-foreign-language students' learning and mastery of English grammar.

It is noteworthy that all of the examples in the Saudi Arabian studies have used asynchronous interaction due to the limitation in the bandwidth in the country. Supporting this view, Al-Dawalij Manager (Saudi Educational Software Producing Company) said that his company had stopped producing online educational materials for schools because of the network connection problems that prevented schools from accessing the material. Thus, their product range is only available on CD-ROMs and DVDs (Abu Hassana and Woodcock 2006).

However, asymmetric digital subscriber line (ADSL) connection has recently become available to homes and businesses in major metropolitan areas in Saudi Arabia, including all universities. This technology, which allows existing telephone lines to be used simultaneously for voice communication and as high-speed Internet access paths, is not yet available in all residential areas. This will affect the selection of tools for the delivery of online instruction, in the short term.

\section{Elements and design of blended learning}

In blended learning, the face-to-face portion is conducted in an instructor-led classroom while the online learning portion could be provided as synchronous or asynchronous. Online synchronous elements could be online chat, video-conferencing, and/or conference calls, and asynchronous elements could be online discussion boards, online tutorials, online self-assessments, electronic texts, and emails.

Lack of supporting technology could be a reason for adopting asynchronous elements instead of synchronous elements as is the case in this study. Asynchronous learning is self-paced, student-centred, and offers students learning materials that can be repeated at their convenience.

Blended learning designs differ according to the elements that are blended, the percentage of these elements in the course credit, and the objectives of the courses. According to Garrison and Kanuka $(2004,96)$, there is a shortage in blended learning designs that can be followed by instructors. They state that "[there] is considerable complexity in its implementation with the challenge of virtually limitless design possibilities and applicability to so many contexts".

As discussed in the rationale for blended learning, students prefer blended learning over online learning. In a study achieved about students and blended learning techniques, Reichlmayr (2005) points out that $72 \%$ of the students liked having part of the course online and part of it in the classroom (17\% disagree, $11 \%$ neutral). Significantly, Danchack (2004) - who redesigned his traditional course to include online synchronous and asynchronous materials - stated that students did not appreciate the instructor's efforts in organising the materials because they expected a certain amount of instructor presence. This raises an issue regarding the percentage of blended elements in the course credit.

Ross and Gage (2006) state that differentiation in the learning process would not depend on if they blend, but rather how they blend. 'How to blend?' is a crucial question that has been considered by researchers to which there may be a vast number of possible answers. There are three categories of blended learning systems based on the primary objective of the blend: 
- First, enabling blends by providing the same opportunity or learning experience but through a different mode where learners choose the option that meets their cost and time constraints.

- Second, enhancing the blend by adopting learning management systems to provide supplementary resources for courses that are mainly conducted face-toface.

- Third, transforming blends by utilising technology-mediated approaches in teaching as a main instruction method combined with traditional learning (Graham 2006).

Moreover, the University of Phoenix offers courses called FlexNet where classes meet one-third of the time in a face-to-face format and two-thirds in an online format. As a result, the face-to-face class time was then transformed into an active discussion session rather than a lecture (Cottrell and Robison 2003). In Brigham Young University, students enrolled in Introductory Accounting watch online videos of live class lectures including explanations of difficult concepts. A different design has been implemented by Brigham Young University, where first-year English students are required to meet face-to-face once a week instead of three times a week. In this design, online modules provide writing instruction and teaching assistants use online and face-to-face contact to provide feedback and guidance on writing (Waddoups, Hatch, and Butterworth 2003).

Another study that has responded to the challenge of delivering tutorials to large classes with timely assessment and feedback had replaced class tutorials by webbased activities. Obviously, this design is especially useful to technical field-ofpractice subjects that aim to teach specific problem-solving skills. The initial findings of the study have shown excellent student performance. However, Rodanski (2006) claims that it is still too early to draw any definitive conclusions and that their approach has to be validated in future research.

\section{Challenges of blended learning}

This section uncovers challenges that Saudi universities may face when implementing blended learning. In general, these challenges can be grouped into three major categories: the culture and blended learning environments; finding the right design; and demand on time (Graham, Allen and Ure 2003). These three main challenges will be addressed individually below.

\section{Culture and blended learning environments}

One major challenge to be considered in the implementation of blended learning in Saudi universities is the adaptation of this element in the traditional university culture. Specifically, the issues that are likely to arise are related to a measure of: the extension of comfort levels related to the use of technology in education; the level of students' self-discipline, organisational and managerial support; student responsiveness (Graham, Allen, and Ure 2003); and society norms and values. Sait et al. (2003) mention that some instructors are against new technological methods as a replacement for face-to-face instructions that revealed a type of instructor resistance that should be taken into consideration. Moreover, Saudi female faculty perceptions regarding the potential use of the Internet were investigated by Al-Kahtani, Ryan, and Jefferson 
(2006) and revealed an interesting conflict of aspects based on age and academic discipline. Conservative elements of the society see the Internet as a danger to societal norms because of its unethical content, while faculty in science disciplines see it as a powerful tool for work enhancement. To overcome faculty negative perceptions of the potential of the Internet, Al-Kahtani, Ryan, and Jefferson's study developed a theory named Internet Technology Acceptance as a theoretical abstraction that has yet to be validated. Undoubtedly, faculty perceptions of the potential use of the Internet influence their attitudes towards blended learning.

Moreover, it may be challenging for Saudi universities to get students to adapt to the use of new learning strategies when they have been used to the traditional didactic, lecture-based classroom. Unlike a traditional approach, blended learning requires a high level of student discipline and responsiveness. A study that was conducted on freshman students argued that some students did not take online instruction seriously as it was not used by other instructors and students at the college (Al-Jarf 2005). Certainly, taking online instruction seriously also requires students to have an adequate level of self-discipline. It may be that applying blended learning programmes to senior undergraduate classes, as a first stage of the blended learning implementation, would help to ensure appropriate levels of student discipline and responsiveness. Some first-year students might need appropriate skills training to achieve success in blended courses.

Moreover, the course instructor may have difficulty in adopting the new learning strategy. This constraint may be overcome by providing orientation and training programmes for faculties. The benefits of blended learning - such as increased learner satisfaction, understanding of materials, reduced training time and the ability to easily update training materials - are powerful reasons for employing blended learning for faculty training programmes. Professional development that teaches instructors strategies of online teaching is also important.

The technical skill level of students and instructors may be a key challenge to implementing blended learning. Because Saudi students have not experienced online learning, a number of students may struggle with acquiring the crucial skills to function well in a blended learning environment. In addition, Sait et al. (2003) reported that instructors with limited skills in Internet usage were hesitant in using any technology in their teaching. In order to address this issue, extensive tutorials, support services, and a helpdesk are a sought for both students and instructors. Institutional support is a way of encouraging faculties to adopt blended learning. The instructors' confidence in using new technology is an important factor influencing the delivery approach, which is equally important to finding the right blend.

\section{Finding the right design}

The flexibility of blended learning addresses varying design needs, and is both a strength and a challenge. For a programme to be blended in design, not just delivery, blended learning requires an intentional approach to instructional design. If there were established design frameworks that could be used as guidelines, it would greatly simplify the task of implementing blended learning. In addition, producing effective and interactive digital contents is another critical issue that challenges instructors of blended courses. The NELC has started to create a digital repository that will contain various educational contents such as 'Learning Objects', and lectures notes that could be uploaded, modified by faculties and retrieved by students (NELC n.d.). This 
project was launched in April 2009 but it cannot be predicted if and how instructors will use these resources.

The decisions made in the design process are critical to the effect the course will have on the learner. However, with such a wide variety of delivery mediums, choosing the best combination of technology is a daunting task for many instructors. In addition, the instructors who aim to implement blended courses may not have enough knowledge about how to ensure their effectiveness and there is a lack of a specific instructional design framework to be used for all curricula. Therefore, it is recommended that the NELC provides a series of easy to use curriculum design ideas for instructors. In addition, the vast new activity resource combination of online and faceto-face learning should be considered within the overall design of the curriculum (Huang and Zhou 2006).

As shown in the design section above, an issue regarding the percentage of blended elements in the course credit is examined because students expect a certain amount of instructor presence (Danchak 2004). Therefore, it is recommended that blended learning programmes require only $25-50 \%$ of the course credit to originate from web-based instruction. This percentage is stipulated in order to retain the advantages of face-to-face instruction. In addition, bandwidth access is a challenge that can be overcome by making required online materials asynchronous instead of synchronous. Also, computer laboratories must be available because some students may not have computers or Internet access at home.

\section{Demand on time}

The time required by instructors who implement blended courses will increase because they must develop digital content and moderate online learning. Transforming traditional courses into blended courses will require more instructor time than developing traditional courses because of the necessity of redesigning the course. Moreover, instructors and students typically incur an increase in the time they spend on learning new techniques and skills, and on interacting with each other in blended learning environments. Instructors will have to adjust their schedules to accommodate more frequent interaction with students who generally expect more frequent feedback in online environments than in face-to-face environments (Graham, Allen, and Ure 2003).

Saudi universities have given high consideration to the development of faculty skills. For example, King Saud University has recently established a Deanship of Skills Development that aims to implement the necessary development programmes to improve the skills of the university staff and support faculty in making use of the latest technology and instructional techniques. However, workshops that consider time management relating to blended learning teaching are highly recommended in order to maximise effectiveness and manage time. Universities should provide timemanagement resources and orientation sessions to outline time-management strategies for both instructors and students in order to overcome this issue.

\section{Conclusions}

Adopting blended learning in Saudi higher education requires thorough exploration of successful stories of blended learning implementation to survey the challenges that have been encountered and to identify specific challenges related to the context. 
Although the studies that were conducted in Saudi Arabia to investigate the effect of online learning and the Internet on education have demonstrated positive attitudes (Sait et al. 2003; Yushau 2006; Al-Jarf 2005), studies on blended learning are still very scarce due to the recent emergence of blended learning. Because the status of higher education in Saudi Arabia necessitates an urgent solution, it is recommended that the transition to a blended learning university environment is facilitated by providing the following: a thorough orientation for new students and instructors; student computers laboratories; instructor training programmes, and a series of easy to use curriculum design ideas for instructors. In addition, it is recommended to use feedback from students and instructors via regular course evaluations and other means to accurately inform university action plans.

This paper identifies a rich field for future research. Blended learning designs could be explored to develop instructional design frameworks that reflect Saudi culture. Further research could inform the faculty development programme for blended teaching based on faculty skills. Obviously, in-depth understanding of the challenges of implementing blended learning should be explored. Finally, although this investigation is specifically related to the implementation of blended learning in the universities of Saudi Arabia, we are confident that the assumptions and recommendations explored in this paper will be relevant to other populations facing similar challenges.

\section{References}

Abdul Ghafour, P.K. 2008. Most Saudi universities switch to e-learning by next year. Arab News, 11 May. http://www.arabnews.com/?page=1\&section=0\&article=109789\&d=11\& $\mathrm{m}=5 \& \mathrm{y}=2008 \&$ pix $=$ kingdom.jpg \& category=Kingdom .

Abu Hassana, R., and A. Woodcock. 2006. Blended learning: Issues and concerns. Paper presented at the Fourth Saudi Technical Conference and Exhibition, 2-6 December, in Riyadh, KSA.

Al-Ahmari, A. 2009. Defending distance learning. Al-Watan Newspaper, 15 March. http:// www.alwatan.com.sa/news/newsdetail.asp?issueno=3089\&id=94199\&groupID $=0$.

Al-Jarf, R.S. 2005. The effects of online grammar instruction on low proficiency EFL college students' achievement. Asian EFL Journal 7, no. 4: 166-90.

Al-Kahtani, N.K.M., J.J.C.H. Ryan, and T.I. Jefferson. 2006. How Saudi female Faculty perceive Internet technology usage and potential. Information Knowledge Systems Management 5, no. 4: 227-43.

ArRiyadh Development Authority. n.d. The population in ArRiyadh City. http://www.ada. gov.sa/Researches/index.asp.

Communications and Information Technology Commission. 2007. Report on number of internet users in Saudi Arabia. Riyadh: CITC.

Cottrell, D., and R. Robison. 2003. Blended learning in an accounting course. Quarterly Review of Distance Education 4, no. 3: 261-69.

Danchak, M.M. 2004. Designing for the changing role of the instructor in blended learning. IEEE Transactions on Professional Communication 47, no. 3: 200-10.

DeLacey, B.J., and D.A. Leonard. 2002. Case study on technology and distance in education at the Harvard Business School. Educational Technology and Society 5, no. 2: $13-28$.

Garrison, D.R., and H. Kanuka. 2004. Blended learning: Uncovering its transformative potential in higher education. The Internet and Higher Education 7, no. 2: 95-105.

Graham, C.R. 2006. Blended learning systems: Definition, current trends, and future directions. In The handbook of blended learning: Global perspectives, local designs, ed. C.J. Bonk and C.R. Graham, 3-21. San Francisco: Pfeiffer.

Graham, C.R., S. Allen, and D. Ure. 2003. Blended learning environments: A review of the research literature. Unpublished manuscript, Provo, UT. 
Graham, C.R., S. Allen, and D. Ure. 2005. Benefits and challenges of blended learning environments. In Encyclopedia of information science and technology, ed. M. Khosrow-Pour, 253-9. Hershey, PA: Idea Group.

Huang, R., and Y. Zhou. 2006. Designing blended learning focused on knowledge category and learning activities: Case studies from Beijing Normal University. In The handbook of blended learning: Global perspectives, local designs, ed. C. Bonk and C. Graham, 296-310. San Francisco: Pfeiffer.

Laster, S., G. Otte, A.G. Picciano, and S. Sorg. 2005. Redefining blended learning. Paper presented at the Sloan-C Workshop on Blended Learning, April 18, in Chicago, IL.

Lionarakis, A., and D. Parademetriou. 2003. The quality of the learning experience: A comparative study between open distance and conventional education. Turkish Online Journal of Distance Education 4, no. 2. http://tojde.anadolu.edu.tr/tojde10/articles/lionarakis.htm.

Ministry of Higher Education. n.d. http://www.mohe.gov.sa.

National E-Learning and Distance Learning Centre. n.d. http://www.elc.edu.sa.

Oliver, R., and J. Herrington. 2003. Factors influencing quality online learning experiences. In Quality education@a distance, ed. G. Davies and E. Stacey, 137-42. London: Kluwer Academic.

Osguthorpe, R.T., and C.R. Graham. 2003. Blended learning systems: Definitions and directions. Quarterly Review of Distance Education 4, no. 3: 227-34.

Owston, R.D., D.R. Garrison, and K. Cook. 2006. Blended learning at Canadian universities. In The handbook of blended learning: Global perspectives, local designs, ed. C.J. Bonk and C.R. Graham, 338-50. San Francisco: Pfeiffer.

Picciano, A.G. 2006. Blended learning: Implications for growth and access. Journal of Asynchronous Learning Networks 10, no. 3. http://www.sloan-c.org/publications/jaln/v10n3/ index_member.asp.

Reichlmayr, T. 2005. Experience with blended learning techniques. Paper presented at the 35th ASEE/IEEE Frontiers in Education Conference, October 19-22, in Indianapolis, IN, USA.

Rodanski, B. 2006. Dynamic web-based tutorial tool. In Proceedings of the IEEE Seventh International Conference on Information Technology Based Higher Education \& Training (ITHET 2006), 67-70. Washington, DC: IEEE Publications.

Rooney, J.E. 2003. Blending learning opportunities to enhance educational programming and meetings. Association Management 55, no. 5: 26-32.

Ross, B., and K. Gage. 2006. Global perspectives on blended learning: Insight from WebCT and our customers in higher education. In The handbook of blended learning: Global perspectives, local designs, ed. C. Bonk and C. Graham, 155-68. San Francisco, CA: Pfeiffer.

Sait, S.M., K.M. Al-Tawil, S.H. Ali, and S.A. Khan. 2003. The use and effect of internet on teachers and students in Saudi Arabia. Paper presented at the Hawaii International conference on Education, January 7-10, in Honolulu, HI.

Sharpe, R., G. Benfield, G. Roberts, and R. Francis. 2006. The undergraduate experience of blended e-learning: A review of UK literature and practice. The Higher Education Academy. http://www.heacademy.ac.uk/research/Sharpe_Benfield_Roberts_Francis.pdf.

Singh, H., and C. Reed. 2001. A White Paper: Achieving success with blended learning, 6. Lexington, MA: Centra Software.

Waddoups, G.L., G.L. Hatch, and S. Butterworth. 2003. Blended teaching and learning in a first-year composition course. Quarterly Review of Distance Education 4, no. 3: 271-8.

Wend, P. 2006. Towards a joined-up student learning experience at Oxford Brookes University. Brookes eJournal of Learning and Teaching 2, no. 1. http://bejlt.brookes.ac.uk/article/ towards_a_joined_up_student_learning_experience_at_oxford_brookes_universit/.

Young, J.R. 2002. 'Hybrid' teaching seeks to end the divide between traditional and online instructions. Chronicle of Higher Education 48, no. 28: A33-4.

Yushau, B. 2006. The effects of blended e-learning on mathematics and computer attitudes in pre-calculus algebra. The Montana Mathematics Enthusiast 3, no. 2: 176-83. 